\title{
ARGENTINE STEM WEEVIL ADULTS ARE AFFECTED BY MEADOW FESCUE ENDOPHYTE AND ITS LOLINE ALKALOIDS
}

\author{
J.G. JENSEN ${ }^{1}$, A.J. POPAY ${ }^{1}$ and B.A. TAPPER ${ }^{2}$ \\ ${ }^{1}$ AgResearch Limited, Private Bag 3123, Hamilton, New Zealand \\ ${ }^{2}$ AgResearch Limited, Private Bag 11008, Palmerston North, New Zealand \\ Corresponding author: joanne.jensen@agresearch.co.nz.
}

\begin{abstract}
Responses of adult Argentine stem weevil (ASW) to meadow fescue infected with the endophyte Neotyphodium uncinatum and to two loline alkaloids produced by the fungus were investigated. Endophyte in two different meadow fescue seed-lines did not affect adult ASW feeding scores but reduced oviposition compared with endophyte-free controls. In a no-choice experiment, adult ASW were given artificial diets containing $\mathrm{N}$-formyl loline (NFL) or N-acetyl norloline (NANL) at three concentrations or a control diet with no lolines. Mortality was significantly higher at the highest rate of NFL than for lower rates and the control. For NANL, mortality was increased at both the lowest and the highest concentrations. Feeding scores were higher on control than loline diets but only after 4 weeks. In a choice experiment, NFL appeared to have no effect on ASW feeding preference, whereas there was less feeding at the highest concentration of NANL compared with the control diet. Keywords: Listronotus bonariensis, Neotyphodium uncinatum, Lolium pratense, Festuca pratensis, n-formyl loline, n-acetyl norloline.
\end{abstract}

\section{INTRODUCTION}

Argentine stem weevil (ASW) (Listronotus bonariensis (Kuschel)) remains an important pest of pasture in New Zealand (Popay \& Thom 2009). Population dynamics of the weevil, primarily mediated through the mobile adult stage, are closely linked with the availability of pasture grasses that are free of the endophytic fungus, Neotyphodium (Barker \& Addison 2006). These authors showed that protection of grasses by the fungus is important even at high rates of parasitism by the introduced parasitoid, Microctonus hyperodae. Neotyphodium endophytes affect insect pests through the production of certain alkaloids, which may have a deterrent or toxic effect.

Meadow fescue (Lolium pratense Gams, Petrini \& Schmidt syn. Festuca pratensis Huds.) is not recognised as an important pasture species in New Zealand because of its poor vigour and persistence compared with ryegrass and tall fescue (Cooper 1996). However, meadow fescue remains an important model system to study, as the grass, when infected with $N$. uncinatum, produces high levels of lolines and no other alkaloids (Justus et al. 1997).

Lolines have broad-spectrum anti-insect effects (Siegel \& Bush 1996; Popay \& Lane 2000; Wilkinson et al. 2000; Schardl et al. 2007) but there is no evidence of mammalian toxicity associated with $N$. uncinatum-infected meadow fescue (Cooper 1996; Siegel \& Bush 1996; Fletcher et al. 2000). N-formyl loline (NFL) is the major loline alkaloid produced by $N$. uncinatum-infected meadow fescue, followed by $\mathrm{N}$-acetyl loline (NAL) and N-acetyl norloline (NANL) (Justus et al. 1997).

The impact of loline alkaloids on ASW adults was tested in a whole-plant bioassay, followed by artificial diet experiments that investigated concentration effects of NFL and NANL. 


\section{METHODS}

Adult ASW were collected from Waikato pasture in late February 2006 for the whole plant experiment and from pasture in Manawatu in July 2008 for the artificial diet experiments. The weevils were maintained in a controlled environment room at $15^{\circ} \mathrm{C}$ with 16:8 h light:dark regime. Weevils were regularly provided with fresh endophyte-free ryegrass and parasitoid larvae and pupae were removed from the containers.

\section{Whole plant experiment}

On 9 May 200610 plants from each of two meadow fescue seed-lines (1 and 2) infected with $N$. uncinatum and a further 10 endophyte-free plants from a third seed-line were planted into commercial potting mix in $9 \mathrm{~cm}$ diameter pots. Plants were 2 months old and their endophyte status had been confirmed by staining and microscopic examination. Six adult ASW were placed onto each pot, except for two endophyte-free and one plant from each of the two seed-lines, which had eight weevils. Plants were covered with cylindrical cages constructed from acetate sheets and fabric mesh. Plants were placed in a randomised block design in a controlled environment room at $20^{\circ} \mathrm{C}$ with $16: 8 \mathrm{~h}$ light:dark and watered from the base as required.

On 29 May, cage covers were removed from the plants and five randomly selected tillers were scored for adult feeding on a scale of $0-7$. Scoring was based loosely on the number of feeding scars present: $1=<2$ feeding scars (FS), $2=2-5$ FS, $3=5-10$ FS, $4=11-15$ FS, $5=16-25$ FS, $6=26-40$ FS and $7=>40$ FS. Scoring also took into account the size of feeding scars and was carried out independently by two people, whose scores were averaged. The number of eggs on each plant was also recorded.

Data were analysed using GenStat by analysis of variance (ANOVA). Means were separated using Fisher's protected least significance test. Using only those plants on which eggs had been laid, the numbers of eggs per plant were also compared using a two sample t-test assuming equal variances.

\section{Loline experiment}

NFL was obtained by serial extraction with methanol of coarsely-milled meadow fescue seed infected with $N$. uncinatum and NANL from tall fescue seed infected with the N. coenophialum strain, AR542. Extracts were acidified with citric acid, concentrated and then partitioned with chloroform. The concentrated extracts were made alkaline with sodium hydroxide then extracted four more times with chloroform. Combined chloroform fractions were concentrated under reduced pressure and purified by a further cycle of acid-base partitioning, followed by isolation by vacuum distillation. Identities were confirmed by mass spectrometry. NFL was shown to be $90 \%$ pure and contained a small amount of NAL, and NANL was 95\% pure. Lolines were received from AgResearch Grasslands on 5 August 2008 , and frozen in a $-20^{\circ} \mathrm{C}$ freezer.

In October 2008, NFL and NANL were added to $20 \mathrm{~g}$ aliquots of an agar-based diet to give concentrations in the final diet of 400,800 or $1200 \mu \mathrm{g} / \mathrm{g}$. A control diet with an amount of water equivalent to that added as loline fractions was also made. In a no-choice experiment, six adult ASW in each of 10 replicate Petri dishes were provided with $10 \mathrm{~mm}$ diameter plugs of diet from one of the seven treatments. Weevils were checked every 3-5 days for 45 days and the number of ASW on diet plugs, survival and a visual feeding score $(0=$ no feeding, $10=$ all diet eaten $)$ were recorded. After 28 days diet plugs were removed and replaced with new plugs of diet from the original batches, which had been stored in the fridge at $4^{\circ} \mathrm{C}$.

Using the same seven treatment diets, a choice experiment was set up with nine ASW in each of six replicate Petri dishes offered a choice between one of the six loline treatments and the control diet. Diet plugs were $10 \mathrm{~mm}$ diameter, except in the control versus $800 \mu \mathrm{g} / \mathrm{g}$ NANL and the control versus $1200 \mu \mathrm{g} / \mathrm{g}$ NANL treatments, where plugs were only $7 \mathrm{~mm}$ diameter because of a shortage of diet. Weevils were monitored every 3-5 days for 17 days, as described for the no-choice experiment.

For both the choice and no-choice experiments, Petri dishes were sealed with Parafilm ${ }^{\mathrm{TM}}$ to maintain humidity and prevent weevils from escaping and were kept in a controlled environment room at $18^{\circ} \mathrm{C}$ with $16: 8 \mathrm{~h}$ light:dark. 
Data were analysed using GenStat by ANOVA, and treatment means compared using Tukey's test. The mean feeding score in the no-choice test was divided by the number of live weevils in the dish at each assessment in order to account for the different number of weevils per dish as a result of mortality during the trial. Feeding scores for the choice test were compared using a paired t-test of difference/SED for each treatment.

\section{Whole plant experiment}

\section{RESULTS}

There was no significant difference in either the mean adult feeding score per tiller or per plant (= mean feeding score/tiller $\times$ number of tillers) (Table 1$)$. There was a considerable difference $(\mathrm{P}=0.081)$ in the mean number of eggs per plant, averaged across all reps (Table 1). Overall, eggs were laid on five endophyte-infected plants (two of seed-line 1 and three of seed-line 2) and five endophyte-free plants. Comparing just those plants on which reproductive ASW were present, an average of 5 eggs/plant was recorded on endophyte-infected plants compared with 21 eggs/plant on endophyte-free plants $(\mathrm{P}<0.05$, $\mathrm{t}$-test $)$.

TABLE 1: Argentine stem weevil adult feeding scores (FS) and oviposition (no. eggs/plant) in two accessions of meadow fescue infected with $N$. uncinatum and an endophyte-free control. Values are the mean of all replicates.

\begin{tabular}{lccc}
\hline & FS/tiller & FS/plant & No. eggs/plant \\
\hline Endophyte-free & 4.2 & 40.1 & 10.7 \\
Seed-line 1 & 3.4 & 56.3 & 1.3 \\
Seed-line 2 & 2.9 & 40.0 & 1.4 \\
\hline Significance (ANOVA) & $\mathrm{ns}$ & $\mathrm{ns}$ & $\mathrm{P}=0.08$ \\
\hline
\end{tabular}

\section{Loline experiment}

Survival of adult ASW was significantly affected by the presence of lolines in the diets (Fig. 1) with mean mortality per dish of up to $57 \%$ at the high rate of NFL compared with $6.7 \%$ in weevils feeding on the control. Mortality was significantly higher $(\mathrm{P}<0.05)$ for weevils fed diet containing $1200 \mu \mathrm{g} / \mathrm{g}$ NFL than those fed on the control diet and lower rates of NFL from 28 days onwards. Conversely, mortality was significantly $(\mathrm{P}<0.05)$ higher in ASW fed on $400 \mu \mathrm{g} / \mathrm{g}$ NANL than in the control, $800 \mu \mathrm{g} / \mathrm{g}$ and 1200 $\mu \mathrm{g} / \mathrm{g}$ NANL treatments from 21, 21 and 24 days respectively. Mortality in the $1200 \mu \mathrm{g} / \mathrm{g}$ NANL treatment was intermediate between the other two NANL treatments, and was significantly greater than the control from 43 days onwards $(\mathrm{P}<0.05)$.

There were no significant differences or consistent trends in the percentage of live weevils found on the diet at assessment times, except at 41 days when there were significantly fewer $(\mathrm{P}<0.05) \mathrm{ASW}$ on the $1200 \mu \mathrm{g} / \mathrm{g}$ NANL treatment than on all other diets (data not presented).

Differences between treatments in the mean feeding score per live ASW did not become significant until after day 28, when fresh diet was provided to ASW (Fig. 2). On day 31 feeding was significantly higher on the control diet than on the two lowest rates of NFL $(\mathrm{P}<0.01)$, and higher than on all concentrations of NANL. These differences were no longer significant by day 41, and on day 43 feeding was higher on $1200 \mu \mathrm{g} / \mathrm{g}$ NFL than on both the control and the lower rates of NFL $(\mathrm{P}<0.05)$. At this last assessment the mean feeding score on the control diet was not significantly different to any of the other loline diets. 


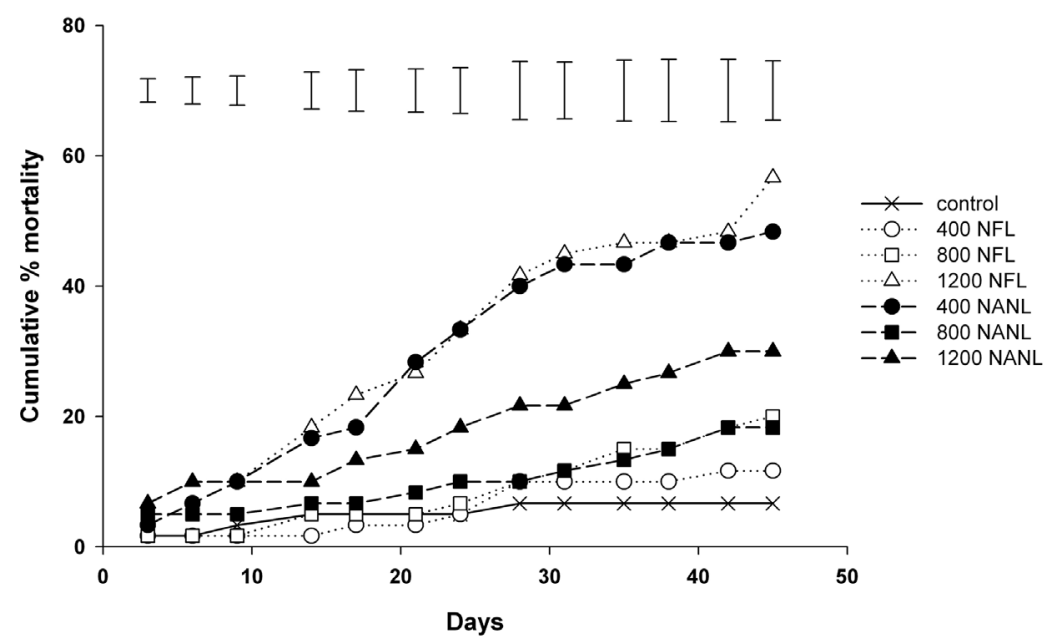

FIGURE 1: Percentage cumulative mortality of adult Argentine stem weevils fed artificial diet containing one of three concentrations of NFL or NANL or a control diet between 17 October and 28 November 2008. Error bars are SED.

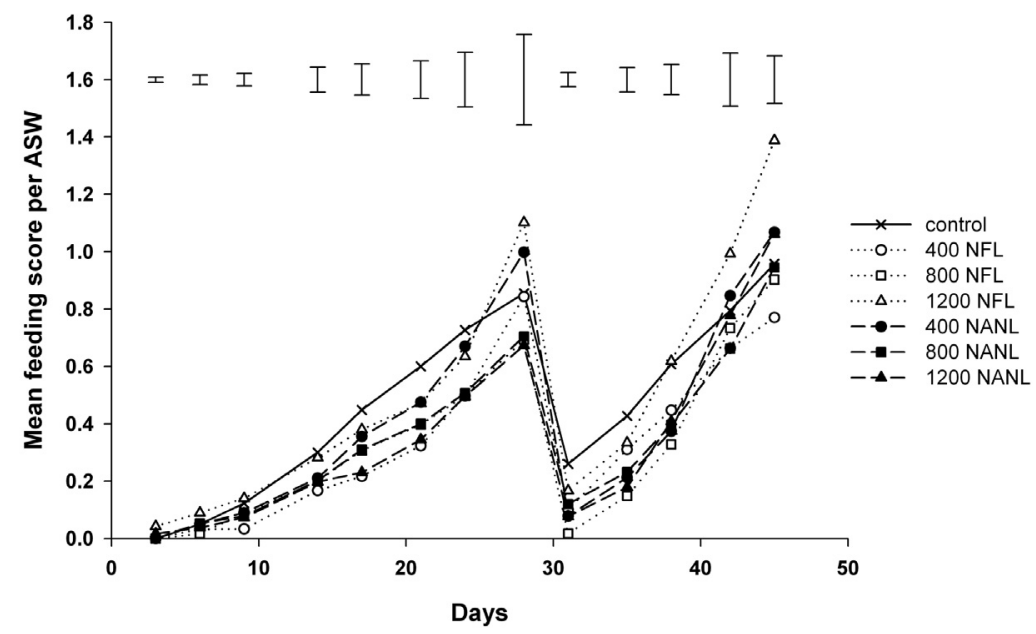

FIGURE 2: The mean feeding score per adult Argentine stem weevil for weevils fed artificial diet containing one of three concentrations of NFL or NANL or a control diet between 17 October and 28 November 2008. Error bars are SED. 
In the choice test, survival was not affected by the presence of the loline diets (data not shown). NFL had no significant effect on feeding by the weevils (Table 2). Feeding scores were significantly higher on the control diet than on the diet containing the highest concentration $(1200 \mu \mathrm{g} / \mathrm{g})$ of NANL $(\mathrm{P}<0.01)$ and this difference was significant from day 6 onwards. Final feeding scores (for day 17) are presented in Table 2. Of the ASW observed on diets at each assessment, the percentage found on the loline diet did not differ significantly between treatments (data not shown).

The higher feeding scores in the 0 versus $800 \mu \mathrm{g} / \mathrm{g}$ NANL and 0 versus $1200 \mu \mathrm{g} / \mathrm{g}$ NANL treatments were most likely an artefact of the smaller plugs of diet used in these treatments. With the visual scoring system used in this experiment, the smaller plugs would have appeared to have higher levels of feeding.

TABLE 2: Mean feeding scores after 17 days for adult Argentine stem weevils offered a choice between a diet containing one of three concentrations of NFL or NANL or a control diet with no lolines.

\begin{tabular}{lccc}
\hline Treatments & Control diet & Loline diet & Significance \\
\hline 0 vs $400 \mu \mathrm{g} / \mathrm{g}$ NFL & 1.8 & 1.3 & $\mathrm{~ns}$ \\
0 vs $800 \mu \mathrm{g} / \mathrm{g}$ NFL & 1.0 & 1.0 & $\mathrm{~ns}$ \\
0 vs $1200 \mu \mathrm{g} / \mathrm{g}$ NFL & 1.8 & 1.3 & $\mathrm{~ns}$ \\
0 vs $400 \mu \mathrm{g} / \mathrm{g}$ NANL & 1.0 & 1.2 & $\mathrm{~ns}$ \\
0 vs $800 \mu \mathrm{g} / \mathrm{g}$ NANL & 4.0 & 3.5 & $\mathrm{~ns}$ \\
0 vs $1200 \mu \mathrm{g} / \mathrm{g}$ NANL & 5.4 & 3.9 & $\mathrm{P}=0.006$ \\
Pooled SED & & & 0.33 \\
\hline
\end{tabular}

\section{DISCUSSION}

In the experiments reported here, the presence of $N$. uncinatum in meadow fescue was found to have no significant effect on adult ASW feeding. NFL, the main loline derivative produced by this endophyte (Bush et al. 1993; Justus et al. 1997) also did not deter adult feeding even at the highest concentration of $1200 \mu \mathrm{g} / \mathrm{g}$. The lack of an effect of $N$. uncinatum on ASW adult feeding contrasts with the results of Patchett et al. (2008a) who reported a negative relationship between adult feeding and loline concentration in a field experiment, although only a marginal difference was found in a choice test between endophyte-free and endophyte-infected plants in a laboratory experiment.

Although no effect of $N$. uncinatum in meadow fescue on adult ASW feeding was detected, the presence of the endophyte caused a significant reduction in oviposition. This is likely to be due to the two to three-fold greater concentrations of lolines in the pseudostem, where eggs are laid, than occur in leaves, where ASW adults feed (Siegel \& Bush 1996; Justus et al. 1997). Since no deterrence by NFL was apparent, the other minor lolines, such as NANL or NAL, may be important for ASW to be able to detect the presence of lolines in infected plants. In the choice test, ASW adults showed a significant preference for feeding on the control diet over the higher concentration of NANL tested. Another possible explanation for the reduced oviposition is a direct effect of the loline alkaloids on fecundity of the weevil.

The large increase in mortality showed that NFL was toxic to ASW adults at the highest concentration. The reduction in feeding at the two lower NFL concentrations that became apparent was also probably indicative of ill health of the weevils caused by feeding on the toxin for an extended period of time. NFL appears to be a slow-acting toxin, as mortality only occurred over a long period of time, although the mortality rate may have been affected by the low amounts of feeding on the diet. 
Results for NANL are less clear, given the highest mortality of ASW occurred at the lowest concentration. A possible explanation is that there was more feeding on this diet giving the weevils more exposure to the toxin. This is not supported by the data, however, with no significant feeding differences in the no-choice test and only the highest concentration of NANL significantly reducing feeding in the choice test. Further work is required to clarify these results.

Previous studies showed no toxic or deterrent effect of $100 \mu \mathrm{g} / \mathrm{g}$ of either NFL or NAL on adult ASW over 6 days (Popay \& Latch 1993). The present results suggest that much higher concentrations of lolines and exposure over a longer period of time are required to have an effect on the adult ASW. It is also possible, however, that the various loline alkaloids could act synergistically to increase any effect on adult ASW. The wet weight loline concentrations tested here are approximately equivalent to 3500,7000 and $10,500 \mu \mathrm{g} / \mathrm{g}$ dry weight. These are much higher than the $400 \mu \mathrm{g} / \mathrm{g}$ dry weight of leaf material that Patchett et al. (2008a) estimated was needed to consistently deter feeding in their field experiment. Reported concentrations of lolines in herbage range from less than $100 \mu \mathrm{g} / \mathrm{g}$ to over $7600 \mu \mathrm{g} / \mathrm{g}$ (Bush et al. 1993; Justus et al. 1997; Wilkinson et al. 2000; Patchett et al. 2008a, b). Although loline concentrations in the meadow fescue plants used in the whole plant experiment described here were not measured, concentrations in $N$. uncinatum-infected meadow fescue of up to $13,500 \mu \mathrm{g} / \mathrm{g}$ of leaf blade and $>20,000 \mu \mathrm{g} / \mathrm{g}$ of leaf sheath have been measured (A.J. Popay, unpubl. data). Thus the concentrations tested in the experiments here were certainly within the range that can be produced by infected plants.

Endophytes such as the commercial strains AR1 (N. lolii) in ryegrass and Max $\mathrm{P}^{\mathrm{TM}}$ (N. coenophialum) in tall fescue produce the alkaloid peramine, which is a powerful feeding deterrent to ASW (Rowan et al. 1990). The presence of peramine-producing endophytes like AR1 results in less adult damage to plants as well as a reduction in oviposition and subsequent larval damage (Popay et al. 2000). In feeding choice trials, Patchett et al. (2008a) showed that a peramine producing $N$. lolii strain in ryegrass strongly reduced adult ASW feeding when compared with $N$. uncinatum in meadow fescue. These results, together with those reported in this paper, suggest that loline alkaloids have quite a different mode of action compared to peramine, reducing oviposition without a marked effect on adult ASW feeding. While fewer eggs will decrease ASW larval populations and damage to plants, subsequent work has shown that the loline alkaloids also affect the larval stage (Popay et al. 2009), further contributing to the protection against ASW that $N$. uncinatum provides for its meadow fescue host.

\section{ACKNOWLEDGEMENTS}

The authors would like to thank Catherine Cameron for data analyses, Colleen Podmore for technical assistance and Tina Eden and Derrick Wilson for providing ASW adults. This research was funded by PGG Wrightson, Grasslanz Technology Ltd and the Foundation for Research, Science and Technology, Contract C10X0815: Exploiting Opportunities from Forage Plant Genomics.

\section{REFERENCES}

Barker GM, Addison PJ 2006. Early impact of endoparasitoid Microctonus hyperodae (Hymenoptera: Braconidae) after its establishment in Listronotus bonariensis (Coleoptera: Curculionidae) populations of northern New Zealand pastures. Journal of Economic Entomology 99: 273-287.

Bush LP, Fannin FF, Siegel MR, Dahlman DL, Burton HR 1993. Chemistry, occurrence and biological effects of saturated pyrrolizidine alkaloids associated with endophytegrass interactions. Agriculture, Ecosystems and Environment 44: 81-102.

Cooper BM 1996. Evaluation of a meadow fescue (Festuca pratensis) population from Northland. Proceedings of the New Zealand Grassland Association 57: 69-72.

Fletcher LR, Popay AJ, Stewart AV, Tapper BA 2000. Herbage and sheep production from meadow fescue with and without endophyte Neotyphodium uncinatum. 4th International Neotyphodium/Grass Interactions Symposium: 447-453. 
Justus M, Whitte L, Hartmann T 1997. Levels and tissue distribution of loline alkaloids in endophyte-infected Festuca pratensis. Phytochemistry 44: 51-57.

Patchett BJ, Chapman RB, Fletcher LR, Gooneratne SR 2008a. Endophyte-infected Festuca pratensis containing loline alkaloids deters feeding by Listronotus bonariensis. New Zealand Plant Protection 61: 205-209.

Patchett BJ, Chapman RB, Fletcher LR, Gooneratne SR 2008b. Root loline concentration in endophyte-infected meadow fescue (Festuca pratensis) is increased by grass grub (Costelytra zealandica) attack. New Zealand Plant Protection 61: 210-214.

Popay AJ, Latch GCM 1993. Prospects for utilising endophytes for grass resistance to insect pests in New Zealand. 6th Australasian Grassland Invertebrate Ecology Conference: $129-155$.

Popay AJ, Lane GA 2000. The effect of crude extracts containing loline alkaloids on two New Zealand insect pests. 4th International Neotyphodium/Grass Interactions Symposium: 471-476.

Popay AJ, Baltus JG, Pennell CGL 2000. Insect resistance in perennial ryegrass infected with toxin-free Neotyphodium endophytes. 4th International Neotyphodium/Grass Interactions Symposium: 187-193.

Popay AJ, Thom ER 2009. Endophyte effects on major insect pests in a Waikato dairy pasture. Proceedings of the New Zealand Grassland Association 71: in press.

Rowan DD, Dymock JJ, Brimble MA 1990. Effect of fungal metabolite peramine and analogs on feeding and development of Argentine stem weevil (Listronotus bonariensis). Journal of Chemical Ecology 16: 1683-1695.

Schardl CL, Grossman RB, Nagabhyru P, Faulkner JR, Mallik UP 2007. Loline alkaloids: Currencies of mutualism. Phytochemistry 68: 980-996.

Siegel MR, Bush LP 1996. Defensive chemicals in grass-fungal endophyte associations. In: Romeo JT, Saunders JA, Barbosa P ed. Recent advances in Phytochemistry. Plenum Press, New York. Pp. 81-119.

Wilkinson HH, Siegel MR, Blankenship JD, Mallory AC, Bush LP, Schardl CL 2000. Contribution of fungal loline alkaloids to protection from aphids in a grass-endophyte mutualism. Molecular Plant-Microbe Interactions 13: 1027-1033. 